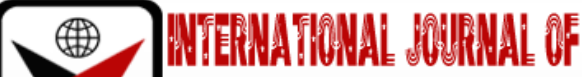 \\ בmRक
}

ISSN 2278-0211 (Online)

\section{Curriculum Change Models and their Resemblance and Suitability for Ghanaian Educational System}

Dr. George Prince Atta
Tutor, Department of Education,
St. Ambrose College of Education, Ghana
Samuel Antwi
Lecturer, Department of Educational Studies,
Kwame Nkrumah University of Science and Technology (KNSUT), Kumasi, Ghana
Thomas Amankwah
Tutor, Department of Education
St. Ambrose College of Education, Ghana
Isaac Kwame Oduro
Tutor, Department of Social Sciences, St. Ambrose College of Education, Ghana
Thomas Okyere
Tutor, Department of Science, St. Ambrose College of Education, Ghana

\section{Abstract:}

This paper reviews some of the curriculum change models and indicates how three of them are similar and suitable for the Ghanaian educational system. The paper begins by considering the nature of the curriculum change model and what necessitates change. Differentiating among concepts such as curriculum, curriculum change, and innovation are considered. Also, strategies influencing curriculum change are outlined. Again, two sets of change models or theoriesEarly models of curriculum change outlined by Schon and New emergent models or theories of curriculum change propounded by Havelock are addressed. The early theories seem to outlive their usefulness due to globalization and advances in knowledge through Information and Communications Technology (ICT). As a result, new emergence theories such as, the Research, Development and Diffusion Model (RD\&D); Social Interaction Model (S.I); Problem Solving Model (S.P), and Linkage Model (L) are reviewed. Furthermore, the National Council for Curriculum and Assessment (NaCCA), as a unit of Ministry of Education and Ghana Education Service responsible for curriculum issues at the pre-university level are examined. Finally, the paper establishes the similarities between RD\&D and NaCCA, and commends Educationists for selecting a suitable model for Ghanaian education system. Other revised or modified models by Nduanya such as, the RD \& D model and Linkage model are suggested to be adopted by NaCCA to assist curriculum development in Ghana.

Keywords: Curriculum, curriculum change, innovation, educational system, model

\section{Introduction}

\subsection{Nature of and what necessitates Curriculum Change}

Society and its institutions continue to be confronted with challenges that, theyeither have to "respond or perish" (Sowell, 2005, p.27).Education as a system "responds to changes" as far as the conditions in its supra-system (i.e., society)" change (Oliver, 2005). Change is both inevitable and necessary in the lives of human beings. Therefore, the school curriculum should change to reflect the needs and aspirations of society. While Sowell (2005) opines thatcurriculum, change is influenced by changes in society, Hoyle (1993), and Emesini, Ogah, and Eze (2013) argue that curriculum change is brought about due to the "findings from sociological studies, psychological investigations of social structures/forces, research in industrial relations, public opinion surveys, and practical curriculum works" (p. 41). They state that information gotten from these sources is used to change and innovate the curriculum. On the part of Oliver (2005), "the curriculum responds to and is changed by social forces, psychological principles, rapid accumulation of knowledge, the nature of the labour market, the presence of persuasive educational groups and individuals, philosophical positions, and educational leadership" (p.29). ToEmesin et al. (2013), curriculum change is necessitated by changes in the social structure of a society.Mkpa (1987: 242), and Agabi (1995: 5), advanced the following reasonsfor curriculum change:

- Cope with pressure and problems from social change;

- Utilize research findings geared towards teaching and learning;

- Explore opportunities with potentials for improved education, and 
- Package an education system that is more relevant to the contemporary situation in Nigeria (cited in Emenzini et al. 2013, pp. 41-42).

It is worth noting that curriculum change is a complex process. Changing the curriculum to suit the needs and aspirations of a particular country or society does not occur overnight, as curriculum planners and specialists startfrom the existing curricula document, and invest so much of their thought, time, and money to work on the new curriculum (Sowell, 2005). Sowell nicely put it this way, "the curriculum planners could heed to the "advice in the Book of Common Prayer, where the believer is told to hold fast to that which is good" (p.38). Not only that, it involves parents, students, teachers, supervisors, administrators, community members or representatives, workers in the schools, and other stakeholders play crucial roles in effecting curriculum change(Sowell, 2005; Oliver, 2005; Emesin et al., 2013, 2013).

\subsection{Defining Curriculum Change and Innovation}

It is necessary for readers, first to understand the concepts of curriculum, curriculum change, and innovation. Curriculum as a concept defies a single universally accepted definition. As such, we will consider a few definitions given by experts. Adentwi (2005) defines curriculum as a "programmethat is intentionally designed to engage learners in activities that will result in educational benefits to them" (p. 14). To Sowell (2005), "curriculum is what is taught to learners. It includes the intended and unintended information, skills, and attitudes that are communicated to learners whether in schools or in other locations where teaching takes place" (p. 14). Arguments advanced by experts on curriculum have generated other understandings of the concept: (a) the ideal curriculum-this is what authorities believe should be taught; (b) the formal curriculum-basically, this is mandated by a monitoring agency such as a state or a country; (c) the perceived curriculum - this is what teachers basically inform the public that they are teaching in response to students; (d) the operational curriculum-this is what supervisors in a local community/area, parents, and other stakeholders/observers clearly see that they are being taught in schools; (e) the experiential curriculum-this deals with the interest of students, their abilities, their learning styles as well as prior experiences (Amimo, Bosire, \& Role, 2014).

According to Patterson and Czajkowski (1979), "curriculum change refers to any conscious, deliberate attempt to bring about change in the curriculum of a school or school system (p. 204). In the words of Leung (2012), curriculum change refers to a set of concepts that include innovation, development, and adoption It therefore involves both planned and unplanned changes that can take place atthe classroom level, school, and the whole system of education. Therefore, curriculum change is seen as a process involving constant support from both the effort of teachers and schools. The expectation is that the critical changes in the curriculum would enhance the professional growth of teachers and schools experiencing the change (Leung, 2012). Other terminologies associated with curriculum change include educational reforms, development and innovation.

According to Harris et al. (1995: 60), innovation refers to "an intentional and deliberate process to bring out desired effects and change." Curriculum innovation describes ideas or practices that are both new and different from the existing ones codified in the formal curriculum.Harris et al. (1995) citing Westerly (1969) and Richard (1965), describe curriculum innovation as "any improvement that is deliberate, measurable, durable and unlikely to occur frequently" (p. 61). "It is the creation, selection, organization and utilization of human and material resources in ways that result in the higher achievement of curriculum goals and objectives." The major difference between curriculum innovation and change is that innovation is always planned, whereas change may occur place in response to external events. Any curriculum innovation is very effective and meaningful when well-planned and organized (Harris et al., 1995).Innovation looks at introducing totally new curriculum aspects, whereas development and reforms refer to a general improvement of what already exists (Amimo, Bosire\&Role, 2014).

Curriculum change takes place at three levels-minor, medium, and major(Otunga, Odero, \&Barasa, 2011; Amimo, Bosire\&Role, 2014). Minor changes deal with re-arranging the sequence of the subject contentor learning activities or just adding one topic or method to the instructional program. Medium changesrefer to the innovation which includes integrating subjects, a new subject or a new approach being added to the existing subject. Major changes affect several aspects of the curriculum, including the content, methods, approaches, materials; adding to or subtracting from the already existing curriculum. Changes could also be seen in the conceptual design and the organization, thereby necessitating a new planning (Otunga, Odero, \&Barasa, 2011; Amimo, Bosire, \&Role, 2014).

\subsection{Strategies for Curriculum Change}

Due to challenges facing education establishments, triedand tested strategies as well as the ways that can be used to implement curriculum change have been advanced by ISN $(2006$, p.28) for senior andmiddle managers. The strategies include:

- $\quad$ Providing effective leadership to drive change

- Making curriculum change a high priority

- Providing support to achieve success

- Planning and resourcing for effective curriculum change

- Ensuring that all learners participate in work-related learning as part of their entitlement

- Working to your strengths and fielding your best team to participate in new curriculum

- Initiatives

- Making use of external partners to achieve successful curriculum change

- Creating a shared approach as a vehicle for effective change

- Recognizing and using staff contributions 
- Disseminating good practice

- Gaining the confidence of staff

- Dealing with negative perceptions of change and professional development

- Using accommodation to promote teamwork

- Recognizing and dealing effectively with staff 'wants' and 'needs.'

\section{A Review of Curriculum Change Models}

A different set of models are employed when a sound curriculum is to be developed. Stenhouse (1957) defines a curriculum model as "a theoretical framework that tends to represent a system or set of related concepts or events in a way that depicts surface features, and highlights essential organization" (p.89, as cited in Emesin et al., 2013). Summarily,a curriculum model could be explained as asystematically laid-down framework representing the essential ways that organizations employ to achieve their goals. Curriculum change models attempt to find answers to certain pertinent questions relating to building and restructuringsome educational programmes. The basic questions posed include, 'why', 'what', and 'how' of education(Emesin et al., 2013; Ivowi, 2008).

Ivowi (2008) distinguishes between the curriculum development model and curriculum change model. Concerning curriculum development, Ivowi notes that the developers are so much concerned with - "What do we need to develop? Why do we need to develop? And, how do we develop the essentials of education"?(Emesin et al., 2013, p.42). On the other hand, with change or innovation models, developers express concern such as - "what do we need to alter? Why do we need to alter them? And how do we go about the change process?" (pp.6-7).

Curriculum change models have been classified into two groups by Ivowi (2008). They include:

- The Schon models popularly called the early theory models

- The Havelock models popularly called the newer emergent models (Emesin et al., 2013).

However, Tanner and Tanner (1980: 262) outline three principal models which depict how change occurs (Jehangir, 2015). These seem to be in line with Havelock models--newer emergent models.

\subsection{The Schon Modelsor Early Theories of Curriculum Change}

Schon (1971) was regarded as one of the pioneers who contributed to the curriculum change theories. Schondeveloped his theory based on improvement in technology at the time. Blenkin, Gwyn, and Kelly (1975) carefully studied Schon's model and found that thecentral focus of Schon was on society and its institutions that were in a constant process of change. Schon concludes that institutions known as learning systems should be developed in such a way that they could come out with their own continuing process of change (Emesin et al., 2013).Schon's main focus was on systemsof diffusion claiming that it was very relevant to the learning capacity of a society. Blenkin et al (1975) and Ivowi (2008) identified three evolving change models from the work of Schon. They include:

$>$ Centre-Periphery Model (CPM).

$>$ The Proliferation of Centres Model (PCM) and

$>$ Shifting Centres Model (SCM) (Emesin et al., 2013)

\subsection{Centre-Periphery Model (CPM)}

Three assumptions characterize this model of Schon:

- That innovation exists and is awaiting diffusion;

- That diffusion is the movement of innovation from centre out to its ultimate user, and

- That diffusion is directed towards centrally managed process of dissemination, training and provision of resources and incentives.

Blenkin and colleagues (1975) posit that the Centre-periphery model (CPM) can be very effective when sufficient resources and energy are generated at the centre; and if a large coverage area is createdand efficient network with respect to generating and monitoring feedback is established (Emesin et al., 2013).

\subsection{Proliferation of Centres Model (PCM)}

This model developed by Blenkin et al. (1975) is an advanced aspect of the centre-periphery model (CPM), basically attempting to pinpoint the limitations as well as the failures of the CPM model. The PCM model maintains the basic principle of the centre periphery structure of the CPM, but introduces two principles or centres-primary and secondary and distinguishes between them. The basic functions of the primary centresof the CPM are to take charge of the different innovations-individuals or originators of ideas, indeed, are expected to spread the information. With respect to the PCM, the functions of the secondary centres are to diffuse the innovations, whereas the primary centers serve as specialists in the training, deploying supports and monitoring the innovation or change.The multiplier effect of the PCM is more than the CPM (Emesin et al., 2013).

\subsection{Shifting Centre Model or Movement Model (SCM)}

The SCM is quite different from the CPM and PCM, in that it has no well-defined centre (centre-periphery systems of diffusion) and centrally established message (Emesin et al., 2013). The centresof this model deal with the "rise" and "fall" of new or emerging issues and leaders. Issues regarding changes in religious doctrines andpolitical evolvements are dealt with by this model (Emesin et al., 2013).

The newer emergent change models will be examined in the next section of the paper. These models were developed because of the major shortcomings in the early change models. 


\subsection{The Havelock Modelsor Newer Emergent Models of Curriculum Change}

Through research, the newer models of curriculum change emerged because of the dislike andoutmoded nature of Schon's early models. A thorough review of the early models by researchers like Blenkin et al. (1975) and Mkpa and Izuagba (2004) analyzed the work of Ronald Havelock (1971) on change models. Through their reviews and analyses, the researchers opined that Havelock concentrated so much on the process of educational changebecause of his love for promoting innovation. In his study, Havelock reviewed more than 4000 empirical studies of innovations(Emesin et al., 2013). After review, Havelock developed four curriculum change models, and many modern authors continue to study and apply them to educational changes in their respective countries. The models include:

- The Research, Development and Diffusion model (RD\&D)

- The social Interaction Model (S.I)

- The Problem-Solving Model (P.S)

- The Linkage Model (L)(Emesini, Ogah,andEze, 2013;Jehangir, 2015; University of Zimbabwe, 1995; Blenkin et al. 1975; Nduanya, 1991; Mkpa and Izuagba, 2004; Anaele, 2008; Ivowi, 2008).

\subsection{The Research, Development and Diffusion Approach/Model (RD\&D)}

In this model, the whole process of change starts from the perspective of the originator or developer who formulates a solution to respond to the needs of a user who has been identified ((Emesin et al., 2013; Jehangir, 2015;Blenkin et al, 1975; Mkpa\&Izuagba, 2004). The model is designed to follow“empirical-rational strategy with substages such as:"basic research; applied research; development and testing of prototypes; mass production and packaging; planned mass dissemination and receipt by the user" (Emesini et al., 2013, p. 43; Anaele,2008, p.72). The RD \&D model develops series of activities to represent the centre-periphery model of curriculum change. In the model, innovation is given birth at the center and is then fed into the system. The processes of change are seenas a 'rational sequence of phases in which innovation is:

- Invented or discovered,

- Developed,

- Produced,

- Disseminated to the user (Jehangir, 2015; The Commonwealth of Learning, 2000;(Emesin et al., 2013).

In the wordsoflvowi (2008), the centre may be likenedto the curriculum development centres like Nigerian Educational Research and Development Council (NERDC) where research is conducted, developed and then diffused into the whole education system.Ivowi, Mkpa and Izuagba (2004) note that ideas or innovations in Nigeria follows this process. Agencies such as NERDC, CESAC, and others develop new curricula for the educational needs of the country, available theories as well as research findings (Emesini et al., 2013; Jehangir, 2015). Schools are seen to be located at the periphery while teachers serve as passive agents. Reconciling with the views of other researchers, Nduanya (1986; 1991) posits that the RD \&D model follows a step-by step process in finding solutions to problems of education: Research; Development; Diffusion and Adoption (Emesini et al., 2013; Jehangir, 2015). Nduanya has presented this in the form of a table. It is interesting to note that the RD\&D model had been used in the Carnegie Project to develop a new Social Studies curriculum in the USA.

\begin{tabular}{|c|c|c|c|}
\hline Planning Research & Development & Dissemination or Diffusion & $\begin{array}{c}\text { Evaluation } \\
\text { (Summative) }\end{array}$ \\
\hline Diagnosis & $\begin{array}{l}\text { Formulation of instructional } \\
\text { objectives }\end{array}$ & Lectures & \\
\hline $\begin{array}{l}\text { Choice of overall } \\
\text { strategy }\end{array}$ & $\begin{array}{l}\text { Development of texts and } \\
\text { materials }\end{array}$ & $\begin{array}{l}\text { Publications Teacher- } \\
\text { orientation and in-service } \\
\text { courses }\end{array}$ & (awareness) \\
\hline $\begin{array}{c}\text { Formulation of } \\
\text { educational } \\
\text { objectives }\end{array}$ & $\begin{array}{c}\text { Development of evaluation } \\
\text { instrument }\end{array}$ & Demonstration & \\
\hline $\begin{array}{l}\text { Repeated testing, } \\
\text { evaluation and } \\
\text { revision of texts and } \\
\text { materials }\end{array}$ & Commercial publication & & \\
\hline
\end{tabular}

Table 1: The RD \& D Process Model

Source: (Nduanya, 1986:104, cited in Emesini et al., 2013)

The model constitutes the basis for a lot of research activity in federal government departments and research laboratories. Concerning the model, there is justification for research because new knowledge is created (Jehangir, 2015). In terms of technology transfer, the idea is that "if the knowledge is there, a user will be found for it" (Jehangir, 2015, p.3). Jehangir indicates that the RD\&D model is quite unique because it relies on a decentralized network of agentswho diffuse ideas and informationfor new technology and facilitate its adoption. The RD\&D model is popular based on the following advantages:

- It is solely based on established research findings

- Materials are adequately tested before use 
- It provides an easy opportunity to train and re-train curriculum implementers

- It uses proven curriculum development processes

- It has appropriate method of selecting specialists and experts in the trial testing of curriculum materials before installation in schools (Emesini et al., 2013, p.44; Nduanya 1986:106-107; Mkpa\&Izuagba, 2004:193; Ivowi, 2008:8; Jehangir, 2015, p.3).

However, the model has failed to produce effective outcomes in other agencies. One challenging aspect of the model is that if there is no network for diffusion and feedback from users, it is extremely difficult to get a comprehensive understanding of the needs of potential usersor even applythe model. Often, very little knowledge is known with respect to the needs of users because little systematic efforts are made to match the needs of users based on available technology (Jehangir, 2015).

\subsection{The Social Interaction Model (SI)}

The S.I. model emphasizes on the spread of an innovation through a social system. The originators of this model were Rogers and Lionberger (Nduanya,1991).It was developed further by Havelock (Emesini et al., 2013). In this model, individuals transmitknowledge through a social or informal network involving colleagues of a profession and friends. Emesini et al. (2013) citing Anaele (2008) posits that the model is based on the influence, judgments, and opinions of people. The S.I. model has an obvious relationship with respect to the processes of the diffusion of new ideas, practices and products (Anaele, 2008; Emesini et al., 2013).On the partofNduanya (1991), the first stage of the model is an awareness creation on the part of the social group involved concerning their needs which will motivate their interest. As such, the social group involved will move swiftly to undertake a study and evaluate the suggested change. They will try it out and if it works perfectly, the innovation will then be adopted (Emesini et al., 2013).

Contributing to the S. I. theory, Mkpa and Izuagba (2004) note that this model presents a planned or unplanned social interaction processto diffuse new ideas or practices. The unplanned process is spreading new ideas or practices via contacts between and among teachers withinan institution or school, among schools, between teachers and supervisors. The planned process of social interaction, states that the diffusion process is started through the organization of courses, conferences, or workshops by agencies. These activities serve as initial support and in-service training needed. At the dissemination stage, the agencies involved will plan or implement their transmission strategies-such as the organization of courses, demonstration, and consultancy services (p.192-193; cited in Emesini et al., 2013).

The model focuses on the diffusion of innovation through social systems in which personal communication is very critical. Concepts associated with this approach includes, opinion leaders, early adopters, among others. The model's approach concerning the diffusion and utilization of ideas has received widespread attention and application over the past 45 years (Jehangir, 2015; The Commonwealth of Learning, 2000; University of Zimbabwe, 1995)

As the name suggests, this model places much emphasis on analyzing the interaction between people to describe the flow of information better. Resource and user organizations form the formal structure, while groups of individuals constitute the informal structure. The interaction between the formal as well as the informal structure to a larger extent dependson the intensity of interpersonal exchange of information (Jehangir, 2015). The network will be more effective if the exchange is greater. The S. I. model focuses on how individualsexchange information, insteadof how organizations can increase the adoption of innovations(Jehangir, 2015; University of Zimbabwe, 1995; The Commonwealth of Learning, 2000). The model stresses how important interpersonal networks of information, opinion, leadership, and personal contact are in the process. It is based on the following:

- Awareness of innovation

- Interest in the innovation

- Trial

- Adoption for permanent use (Jehangir, 2015, p. 6; University of Zimbabwe, 1995; The Commonwealth of Learning, 2000).

Emesini et al. (2013)citing Mkpa and Izuagba (2004:195) outline the advantages of the social interaction model as:

- That teachers are directly involved in some social network, so they can run with the innovation vision;

- The S.I. model is flexible because social interaction occurs in diverse forms, formally or informally; so, it gives room for more diverse ways of disseminating and adopting an innovation.

- The process is natural as it deals with the formal communication pattern of mankind (p.45)

\subsection{The Problem-Solving Model (PS)}

Lippitis is recognized as the originator of this mode. Havelocklater developed it in 1971. The model is also known as the Need Reduction Model and is seenas a user-friendly model by Havelock. Havelock's two models earlier discussedRD\&D and Social Interaction Model (S. I.) is based on the assumption that an innovation exists when it has been well developed and disseminated to a passive user (Emesini et al., 2013). Mkpa and Izuagba (2004) posit that this model assumes that an innovation is an aspect of the problem-solving approach---it begins with a need that is translated into a problem. The authors state that the problem should be well diagnosed and solutions found to them.

The P.S model is associated with the normal problem-solving process which subsumesall the central stages in the need elimination process is comparable to the social interaction approach. The implication is that once a need is felt, it is perceived instantly as a problem that needs to be resolved. In an attempt to find solutions to the problems, alternative choices are outlined and the best is selected to solve the problem. According to Havelock (1971), the last stage of the model is the adoption and solution. Blenken and colleagues (1975) indicate that the model is user-friendly because the user is seen as the initiator rather than the recipient of the change, as recognized in the RD\&D model and the Social 
Interaction Model (S. I.). The authors stress that any outsider-individual orgroup coming into the process will play the role as a consultant or collaborator(Emesini et al., 2013). Havelock posits that the model is very important to educational practitioners.

The P.I. Model is developed around the user of the innovation, and follows these steps:

- Determine the problem.

- Search for an innovation.

- Evaluate the trials.

- Implement the innovation (Jehangir, 2015; University of Zimbabwe, 1995; The Commonwealth of Learning, 2000).

The following advantages have been outlined by Mkpa and Izuagba (2004) for the P.S. Model:

- Since teachers who will implement the said changes or innovations are active participants, they are likely to be more committed in their implementation;

- The model is so flexible that it can apply to various aspects of the curriculum like teaching methods and materials, and

- As the innovation is school based, it is designed in such a way that it will be able to meet the need of the school in question (Emesini et al., 2013, p.45).

\subsection{The Linkage Model (L)}

This model tries to integrate the other three models discussed so far-Research, Development and Diffusion Model (RD\&D), Social Interaction Model (S. I.), and the Problem-Solving Model (P. S.). The model attempts to unite as well as integrate the three models by stressing on the "need to link procedures and agencies in a harmonious approach (Emesini et al., 2013; Anaele, 2008) This could take place by linking up with agencies that can provide resources to users, and connect them with more remote resource agents. Anaele reiterates that these resources may include "curriculum materials from a central agency, consultancyservices, or information about other users with related experiences or interests" (p. 72).

Mkpa and Izuagba (2004) in their contribution opine that the linkage model triesto unify the strengths of the three models discussed, and works to overcome their inherent weaknesses. To them, the linkage process focuses on the link that exists between the school and other specializedagencies. The agencies major task is to assist in locating important humanand material resources that will be needed to resolve any problem that arises in the school situation.Mkpa and Izuagba,and Anaele have suggested examples of linkagecentres such asProfessional Centres, Resource Centres, ICT centres, and Exam Centres, etc. These agencies serve as a "linkage points between the national agencies of curriculum development, change and innovating schools, to provide consultancy services, and to offer in-service training for teachers as end users" (Emesini et al., 2013, p. 46).

\section{Nature and Role of National Councilfor Curriculum and Assessment (NaCCA) of Ghana}

In Ghana, as pertains in other countries like France, the legal authority to make decisions in education, including the curriculum is the central governmentsole responsibility. As an agency of the central government, the Ministry of Education has the responsibility for ensuring that curriculum policies and plans are designed for the effective functioning of the educational system (Oduro-Okyireh, 2017; Adentwi\&Sarfo, 2011). As a subsidiary of the Ministry of Education, theCurriculum Research and Development Division (CRDD)was established in 1974. It was renamed the National Council for Curriculum and Assessment (NaCCA) in2008. This body is mandated to carry out curriculum development project. It is in charge of planning the curriculum guidelines and frameworks. Also, the body produces syllabuses, textbooks, teachers' handbooks, head teachers' handbooks, and other teaching and learning materials to be used by all pre-university institutions in the country (Oduro-Okyireh, 2017; Adentwi\&Sarfo, 2011). Again, the body in collaboration with the Ghana Education Service (GES) supervises the trials of newly produced curriculum materials and monitors their implementation via a network of subject organizers/circuit supervisors who are connected to the district education offices in the country.

The NaCCA is constituted by a group of curriculum and instructional design experts and subject specialists of all the subjects offered in the schools across the country. In performing its responsibilities, however, the body constitutes subject panels of representatives of the subject associations, the Ghana National Association of Teachers (GNAT), subject specialists, and curriculum design experts from the universities of education. Other agencies may have their representatives to serve on the subject panels--they include the National Advisory Committee on Curriculum for PreUniversity Education, the West African Examinations Council (WAEC), the National Accreditation Board (NAB), the Ministry of Employment and Social Welfare, the National Teacher Training Council (NTTC), the Bureau of Ghana Languages (BGL), and the Concerned Parents Association of Ghana (CPAG) (Oduro-Okyireh, 2017; Adentwi\&Sarfo, 2011; Adentwi, 2005).

\subsection{Establishing Curriculum Change Models Resemblance and Suitability for Ghanaian Education System}

A thorough examination of the four newer curriculum change models of Havelock presented thus far, the RD\&D model and its process are similar to NaCCA and suitable for the Ghana education system. Authorities like Ivowi (2008) and Bishop concur that the RD\&D model is a common curriculum change model which is quite suitable for developing countries (Emesini et al., 2013), including Ghana.

Like the RD \&D model, NaCCA takes full responsibility for planning the curriculum and its frameworks in Ghana.NaCCA develops new curriculum materials (i.e., teaching and learning materials) on a large scale and disseminates them to schools considered to be in the periphery. The mass production of materials reduces unit cost, if individual schools 
were to produce materials independently, the cost would beexpensive. Both RD \&D and NaCCA are at the centre and the schools are at the periphery.

Also, NaCC Aresembles the RD\&D model in the sense that it undertakes intensive research activities and trial-test newly developed curriculum materials. It monitors their execution at the district levels. Again, like the RD\&D model, $\mathrm{NaCCA}$ as a body puts together instructional design experts and subjects' specialists from subject associations, teachers' unions and the universities of education to develop the curriculum for Ghana.

In addition, NaCCA resembles the RD\&D model because it follows a step-by-step development of activities representing the centre-periphery approach of change. To Ivowi (2008), the idea or innovation is formulated at the centre. Aside the RD \&D model, other models such as the Linkage model, S.I. model and the P.S. model are similar and suitable for the Ghana education system because they have been modified as well as having special approaches of reducing the anomalies of the other models (Emesini et al., 2013; Nduanya, 1986; Mkpa\&Izuagba, 2004).

The modifications outlined by the authors include:

With respect to the RD\&D model, the involvement of teachers is quite low; similarity is assumed between schools and; it is mainly suitable for the production of materials (Emesini et al., 2013). However, concerning the modifications of the linkage models: Teachers are made to participate greatly; differences in schools are considered; it is for all types of innovation in curriculum change; the emphasis being placed on the functional groups who are involved; working relationships among groups evolve; and systematic network is designed to facilitate dissemination of innovation (Emesini et al., 2013).

Lastly, the Problem-Solving model has these problems: Low quality materials may be produced; teachers spent a lot of their time during curriculum innovation; and educational theory as well as research may be weak (Emesini et al., 2013).

In an attempt to reduce the deficiencies of the linkage model, the following are outlined: Teachers are involved in producing good quality teaching and learning materials; the necessary support is provided for the development of appropriate theory for research; and time is saved as the agency comes out with tried and tested innovations (Emesini et al., 2013).

\subsection{Conclusion}

This paper examined curriculum change models and how they are similar and suitable for the Ghana education system, especially at the basic and senior high school levels. It also reviewed the meanings of curriculum; curriculum change and innovation. Also, strategies for curriculum change were outlined. In every country, curriculum change and innovation are necessary because society is not static, but dynamic. So, the curriculum should be designed to reflect the needs and the aspirations of society, especially in this age of technology explosion. Sowell (2005) states that curriculum change is influenced by changes in society-- economic structures, social structures, cultural aspects and research findings, among others.

Again, the paper reviews curriculum changes models such as the early models presented by Schon--CentrePeriphery Model; Proliferation of Centres and Shifting Centres models. The first two--Centre-Periphery Model and Proliferation of Centres Model have certain things in common as diffusion is observed from the center to the periphery, however, the difference is seen in the Proliferation model between its primary and secondary centres. Fixed diffusion centres are absent in the Shifting Centres model, as it keeps on changing as different governments attempt to introduce their change process when the need arises (Emezini et al, 2013).

New emergent models have been developed as the early curriculum change models could not survive global trends due to the advances in knowledge through Internet and Communication Technology (ICT)

Havelock in 1971 made the emergent models popular after reviewing more than four thousand (4000) empirical studies. Havelock identified four (4) models of change, namely: The Research, Development and Diffusion Model (RD \& D), the Social Interaction Model (S.I), the Problem- Solving Model (P.S.) and the Linkage Model (L). In the RD \& D model, research processes are observed in developing and disseminating innovation in the curriculum. The S.I. model prefixes assumptions on both planned and unplanned interaction taking place in social structure in order to disseminate innovation. The P.S. model deals with a systematic diagnosis of problems, presentation and dissemination of innovation procedures. Lastly, the linkage model attempts to put together the strengths of the first three models while compensating for their weaknesses

The last part of the paper considers the various curriculum models and attempts to present three similar and suitable models for the Ghana education system. The R D \& D model is given prominence because it resembles NaCCA, and is applicable because it provides detailed procedures through research dealing with curriculum innovation. Also, the Linkage model was considered similar and suitable because of its new development and remedying effects on the other curriculum models.

The paper concludes that NaCCA is similar to RD \& D model and therefore follows a suitable model. It is obvious that the curriculum developers in the country (Ghana) had chosen an appropriate and suitable model for the country. It suggests that the modified version of RD\& D and the Linkage models should be adopted to form an ideal, formidable, and robust curriculum change models for the Ghanaian educational system.

\section{References}

i. Adentwi, K. I., \&Sarfo, F. K. (2011). Curriculum development: An introduction. Kumasi: EbensPress Ltd.

ii. Adentwi, K. I. (2005).Curriculum development. An introduction. Kumasi: Wilas Printing Press Ltd. Ghana. 
iii. Amimo, C. A., Bosire, J., Role E. (2014). Theoretical Underpinnings of Curriculum Change in Developing Economies: Is Complexity Theory the New Wine in Lewins' Old Wineskin?International Journal of Academic Research in Progressive Education and Development, Vol. 3 (3) (Special Issue). DOI: 10.6007/IJARPED/v3i3/950 URL: http://dx.doi.org/10.6007/IJARPED/v3-i3/950

iv. Blenkin, G.M.; Gwyn, E. and Kelly, A.V. (1975). Change and the curriculum. London: Hodder and Stoughton Group.

v. Emesini, N. O., Mary E. U. Ogah, M. E. U., Eze S. O. (2013). Curriculum change models and their suitability in the Nigerian education system.International Researcher, 2 ( 3), 41-48.

vi. Havelock, R.G. (1971). Planning for innovation through dissemination and utilization of knowledge. Michigan: University of Michigan Institute for Social Research.

vii. Hoyle, S. (1993).Innovation and the social organization of the school. Paris: OECD/CERI Press.

viii. Ivowi, U.M.O. (2008). Curriculum and the total person. A keynote address delivered at 21st Annual Conference of the Curriculum Organization of Nigeria held at the NERDC, Sheda- Abuja. 19th to 20 September.

ix. Mkpa, A.M. (1987). Curriculum development and implementation Owerri: Totan Publishers Ltd.

X. Mkpa, A.M. and Izuagba, A.C. (2004). Curriculum studies and innovation Enugu: Book-

xi. Konsult.

xii. Nduanya, M.O. (1986). The process of curriculum planning II: The research and development process. In Nduanya M.O. (ed) Curriculum studies. Ibadan: Heinemann Educational Books (Nig) Ltd. '99 - 110

xiii. Nduanya, M.O. (1991). Planning for innovation in education in Wazurike, C.N.andNdu, A.N. (eds) Educational planning and national development (A Nigerian Perspective). Awka: Meklink Education Book Series.

xiv. Oduro-Okyireh, G. (2017). Introduction to philosophy of education and school curriculum: Aprimer for diploma and degree courses. Abundance of Grace Ltd.

xv. Stenhouse, L. (1975). An introduction to curriculum research and development. London: Heinemann Educational Books Ltd.

xvi. The Commonwealth of Learning (2000). Curriculum theory, design and assessment.The Southern African Development Community.

xvii. Patterson, J. L., Czajkowski, T. J. (1979). Implementation: Neglected phase in curriculum change. Educational Leadership.

xviii. University of Zimbabwe (1995). Curriculum Implementation, Change and Innovation. (Module EA3AD 303). Harare: Centre for Distance Education, University of Zimbabwe. 